\title{
Lateral Wall Histopathology and Endocochlear Potential in the Noise-Damaged Mouse Cochlea
}

\author{
Keiko Hirose $^{1,2}$ and M. Charles Liberman ${ }^{3,4}$ \\ ${ }^{1}$ Department of Otolaryngology and Communicative Disorders, Cleveland Clinic Foundation, Cleveland, OH 44195, USA \\ ${ }^{2}$ Department of Neurosciences, Cleveland Clinic Foundation, Cleveland, OH 44195, USA \\ ${ }^{3}$ Eaton-Peabody Laboratory, Massachusetts Eye and Ear Infirmary, Boston, MA 02114, USA \\ ${ }^{4}$ Department of Otology and Laryngology, Harvard Medical School, Boston, MA 02114, USA
}

Received: 01 July 2002; Accepted: 31 December 2002; Online publication: 28 March 2003

\section{ABSTRACT}

Noise exposure damages the stria and spiral ligament and may contribute to noise-induced threshold shift by altering the endocochlear potential (EP). The aim of this study was to correlate lateral wall histopathology with changes in EP and ABR thresholds. CBA/CaJ mice were exposed to octave band $(8-16 \mathrm{kHz})$ noise for $2 \mathrm{~h}$ at intensities ranging from 94 to $116 \mathrm{~dB}$ SPL and evaluated $0 \mathrm{~h}$ to 8 weeks postexposure. EP in control mice averaged 86 and $101 \mathrm{mV}$ in apical and basal turns, respectively. The $94 \mathrm{~dB}$ exposures caused a $40 \mathrm{~dB}$ temporary threshold shift (TTS), and there was with no corresponding change in EP. The 112 and $116 \mathrm{~dB}$ exposures caused $>60 \mathrm{~dB}$ threshold shifts at $24 \mathrm{~h}$, and EP was transiently decreased, e.g., to 21 and $27 \mathrm{mV}$ in apical and basal turns after $116 \mathrm{~dB}$. By 1 week postexposure, EP returned to control values in all exposure groups, although those exposed to 112 or $116 \mathrm{~dB}$ showed large permanent threshold shifts (PTS). Cochleas were plastic-embedded and serialsectioned for light microscopic and ultrastructural analysis. Acute changes included degeneration of type II fibrocytes of the spiral ligament and strial edema. The strial swelling peaked at $24 \mathrm{~h}$ when significant EP recovery had taken place, suggesting that these changes reflect compensatory volume changes. In the chronic state, massive loss of type II fibrocytes and degeneration of strial intermediate and marginal

Correspondence to: Keiko Hirose - Department of Neurosciences • Cleveland Clinic Foundation NC-30 • 9500 Euclid Avenue $\cdot$ Cleveland, OH 44195. Telephone: (216) 445-5964; fax: (216) 444-7927; email: hirosek@ccf.org cells was observed with drastic reduction in membrane surface area. The results suggest that EP shifts do not occur with TTS and also do not add significantly to PTS in the steady state. However, EP loss could contribute to acute threshold shifts that resolve to a PTS. EP recovery despite significant strial degeneration may be partly due to decreased transduction current caused by hair cell damage.

Keywords: acoustic trauma, stria vascularis, spiral ligament, cochlea

\section{INTRODUCTION}

Histopathology in noise-induced hearing loss has been studied extensively in both mammalian and avian species. Although some of the earliest investigations of important structural changes in acoustic injury evaluated all structures of the inner ear, most recent attention has focused on damage to the sensory cells and neurons. It is clear that hair cell loss and stereocilia damage are fundamentally important in the etiology of chronic threshold shifts (Robertson and Johnstone 1980; Robertson 1982; Liberman and Dodds 1984; Henderson et al. 1994) and that excitotoxic damage to afferent neurons may contribute to acute threshold shifts (Robertson 1983; Puel et al. 1998). Much less is known about how damage to accessory structures, such as the stria vascularis and spiral ligament, contributes to noise-induced hearing loss in cases of either permanent threshold shift 
(PTS) or temporary threshold shift (TTS) caused by exposure to noise.

Although studied less extensively, structures of the lateral wall, i.e., the stria vascularis and the spiral ligament, can also be damaged by noise exposure or by aging (Liberman and Kiang 1978; Gratton and Schulte 1995; Gratton et al. 1996; Spicer et al. 1997; Ohlemiller et al. 1999; Ichimiya et al. 2000; Hequembourg and Liberman 2001). In turn, lateral wall structures, in particular, the stria vascularis, are critical in maintaining ion homeostasis of the endolymph (Offner et al. 1987; Salt et al. 1987; Wangemann 1995; Wangemann et al. 1995; Takeuchi and Ando 1998). The presence of $\mathrm{Na} / \mathrm{K}-\mathrm{ATP}$ ases and $\mathrm{Na} / \mathrm{K} / \mathrm{Cl}$ cotransporters in the fibrocytes of the spiral ligament suggest that the ligament also plays a key role in the maintenance of the ionic environment and the endocochlear potential (Schulte and Adams 1989; Spicer and Schulte 1996; Crouch et al. 1997). Previous studies have shown that noise exposure can lead to reductions in the EP (Vassout 1984; Ide and Morimitsu 1990; Wang et al. 1992; Boettcher and Schmiedt 1995; Ma et al. 1995; Li et al. 1997). Given the importance of the EP to normal cochlear sensitivity (Sewell 1984), noise-induced histopathology in the lateral wall could contribute significantly to noise-induced hearing loss. If lateral wall structures do contribute to noise-induced hearing loss, then understanding the mechanisms underlying this damage could provide a novel method of intervention, independent of efforts to preserve hair cell integrity, and could potentially lead to strategies to prevent hearing loss after acoustic overstimulation.

Although previous studies have separately documented (1) noise-induced lateral wall histopathology, (2) noise-induced sensory cell damage, (3) noise-induced EP shifts, or (4) noise-induced threshold shifts, none has examined all four issues in the same ears. Similarly, no previous study has simultaneously examined all the cell types of the lateral wall which could be important to the generation and maintenance of normal EP and endolymphatic ionic composition, i.e., including both stria vascularis and spiral ligament. Thus, there are still a number of important unanswered questions, such as (1) whether EP shifts contribute to reversible threshold shifts or, alternatively, whether they appear only when the damage is severe enough to lead to a permanent loss; (2) whether noise-induced EP shifts, and the attendant threshold shifts, ever occur in ears in which the sensory cells and neurons have not been damaged; and (3) whether lateral wall degeneration correlates with loss of EP and whether EP loss is typically accompanied by visible histopathology in the lateral wall.

To address these questions, the present study assessed EP magnitude and cochlear threshold shifts, as well as light and electron microscopic histopathology of the lateral wall, in mice exposed to noise resulting in TTS in some groups and moderate to severe PTS in others. Survivals were $0 \mathrm{~h}$ to 8 weeks after noise exposure to provide insight into the dynamics of injury and repair.

The CBA/CaJ mouse was used as the animal model for a number of reasons. First, the genetic homogeneity of inbred strains such as CBA/CaJ is associated with less interanimal variability in the response to acoustic injury, allowing a clearer picture of injury dynamics to emerge from evaluation of groups sacrificed at a range of postexposure times (Ou et al. 2000; Yoshida et al. 2000; Wang et al. 2002). Second, the availability of interesting transgenic mice in which particular genes have been knocked out or overexpressed is a powerful tool with which to study the mechanisms of acoustic injury (Ohlemiller et al. 1999; Hakuba et al. 2000; Prosen et al. 2000). Third, our laboratory has recently completed a quantitative light microscopic evaluation of the noise-induced patterns of cellular damage and threshold shift in this mouse strain as function of postexposure survival following exposure to a wide range of sound levels (Wang et al. 2002). This background information provides a valuable overview in which to consider the fine details of morphology revealed by the type of ultrastructural analysis used in the present study.

\section{METHODS}

\section{Experimental groups}

Male CBA/CaJ mice aged 10-12 weeks were used in the present study. Animals were randomly assigned to serve as controls or as noise-exposed subjects, and two parallel groups were studied. One group of controls and noise-exposed subjects were used for electron microscopic analysis $(n=30)$. The second group of controls and noise-exposed animals underwent endocochlear potential measurement $(n=98)$. Light microscopic histological analysis was performed in selected ears of this second group to localize the insertion point of the electrodes and to determine integrity of the reticular lamina. All animal procedures were approved by the IACUC of the Massachusetts Eye and Ear Infirmary.

\section{Noise exposure}

Animals were exposed, unanesthetized, and unrestrained within cages suspended inside a reverberant box. The stimulus for noise exposure was an octaveband noise $(8.0-16.0 \mathrm{kHz})$ presented at 94, 100, 106, 112 , or $116 \mathrm{~dB}$ SPL for $2 \mathrm{~h}$. The exposure stimulus was generated by a custom-made white noise source, 
filtered (Brickwall Filter with a $60 \mathrm{~dB} /$ octave slope), amplified (Crown power amplifier), and delivered (JBL compression driver) through an exponential horn fitted to a hole in the top of the sound exposure box. Sound exposure levels were measured at four positions within each cage using a $1 / 4$ in. Bruel \& Kjaer condenser microphone. Sound pressure was confirmed to vary by $<0.5 \mathrm{~dB}$ across these measurement positions.

\section{Anesthesia and surgical preparation}

For auditory brainstem response (ABR) measurement followed by intravascular perfusion or endocochlear potential measurement, mice were anesthetized with xylazine $(20 \mathrm{mg} / \mathrm{kg} \mathrm{IP})$ and ketamine $(100 \mathrm{mg} / \mathrm{kg}$ IP).

\section{ABR tests}

ABRs were evoked with tone pips and recorded via needle electrodes inserted through the skin (vertex to ipsilateral pinna near tragus with a ground on the back near the tail). Stimuli were $5 \mathrm{~ms}$ pips $(0.5 \mathrm{~ms}$ rise-fall with a $\cos ^{2}$ onset envelope, delivered at $40 /$ s). The response was amplified $(10,000 \mathrm{X})$, filtered $(100 \mathrm{~Hz}-3 \mathrm{kHz})$, and averaged with an A-D board in a LabVIEW-driven data-acquisition system. Sound level was raised in $5 \mathrm{~dB}$ steps from roughly $10 \mathrm{~dB}$ below threshold up to $80 \mathrm{~dB}$ SPL. At each sound level, 1024 responses were averaged (with stimulus polarity alternated). The software averager included an artifact reject feature in which response waveforms were discarded if the peak-to-peak voltage exceeded $15 \mu \mathrm{V}$. ABR thresholds defined as the lowest sound level at which the response peaks were clearly present were read by eye from stacked waveforms obtained at $5 \mathrm{~dB}$ sound pressure intervals. Thresholds typically corresponded to a level one step below that at which the peak-to-peak response amplitude began to rise.

\section{Endocochlear potential measures}

For EP recording, a tracheotomy was performed under deep anesthesia. A silver-silver chloride reference electrode was placed under the skin of the dorsum, and the animal was secured in a head holder. An incision was then made in the inferior portion of the right postauricular sulcus; the bulla was perforated allowing for exposure of the stapedial artery, basal turn, and upper turn of the cochlea. An area of bone roughly $0.5 \mathrm{~mm} \times 0.5 \mathrm{~mm}$ was then shaved off the otic capsule with a microscalpel, which was fashioned by grinding a \#6700 Beaver blade to a $0.33 \mathrm{~mm}$ spatulate chisel. A micropipette electrode (10-20 MO) filled with $150 \mathrm{mM} \mathrm{KCl}$ was advanced through the bony aperture into the spiral ligament using a motorized microdriver. The signal was amplified X10 through a Dagan cell amplifier. DC potentials were recorded via an A-D converter coupled to a desktop computer while advancing the electrode in $3 \mu \mathrm{m}$ steps. The EP was recorded when three criteria were met:(1) a rise in potential of greater than $10 \mathrm{mV}$ was observed over a distance of $6 \mu \mathrm{m}$ or less, 2) the positive potential was maintained for $2 \mathrm{~min}$ at a fixed position, and (3) the potential returned to 0 when the electrode was retracted to its original position. A second recording was made in the apical turn of the same ear. The left ear of the same mouse was then tested, using the apical turn for the third recording and the basal turn for the fourth recording. The duration of the entire procedure was typically 30-40 $\mathrm{min}$.

\section{Histological preparation}

Animals were endocardially perfused with $2.5 \%$ glutaraldehyde and $1.0 \%$ paraformaldehyde in a $0.065 \mathrm{M}$ phosphate buffer. Both petrous temporal bones were extracted and the round and oval windows opened to allow intra labyrinthine perfusion of fixative. After overnight fixation at $4^{\circ} \mathrm{C}$, cochleas were decalcified (0.1 M EDTA with $0.4 \%$ glutaraldehyde) for 3 days and then postfixed in osrnium $\left(1 \% \mathrm{OsO}_{4}\right.$ in $\left.\mathrm{dH}_{2} \mathrm{O}\right)$ for $60 \mathrm{~min}$. Cochleas were dehydrated through a graded ethanol series and propylene oxide and then embedded in Araldite resin. The plastic blocks were sectioned at $40 \mu \mathrm{m}$ in a roughly horizontal plane parallel to the spiral axis of the modiolus. Each section was mounted and coverslipped in Permount. After light microscopic analysis, selected sections were floated off slides in xylene and remounted for ultrathin sectioning. For analysis using the electron microscope, the ultrathin sections were mounted on formvar-coated slot grids, stained with lead and uranyl acetate, and examined with a Philips CM10 electron microscope.

\section{Morphometric analysis}

For each case, the cochlear spiral was reconstructed in 3D using Neurolucida ${ }^{\circledR}$ (MicroBrightField, Colchester, VT) software and tracking the heads of pillar cells as the reference point for cochlear lengths. From these 3D data, the distance from the base was computed for each section through the duct using custom software. Cochlear location was converted into frequency according to frequency-map data described by Ehret (1983) which was fit to a mathematical equation $f(\mathrm{kHz})=3.109 *\left(10^{(100-d) * 0.0142}-0.7719\right)$, where $d=$ percent distance from the cochlear base. 
Hair Cell Counts. A standard cytocochleogram was prepared for each ear using high-power oil-immersion objectives and Nomarski optics. In every section through the cochlear duct, the number of present and absent hair cells was assessed throughout the entire section thickness. Evaluation of both the nuclear and cuticular regions was used to make these assessments.

Stria vascularis; light microscopic analysis. The crosssectional area of the stria vascularis was measured in four cochlear regions. In each ear, sections representing the best cross-section through each half turn of the cochlear spiral were identified from the 3D reconstructions. In each of these sections, the stria was outlined via a drawing tube with a $20 \mathrm{X}$ objective, and the cross-sectional area was determined by computerized planimetry.

Electron microscopic analysis. Electron micrographs of midmodiolar cross-sections through the stria, imaged at $3200 \times$, were selected and digitized at $600 \mathrm{dpi}$. At this magnification, the entire width of the stria can be seen, although only a portion of its height (perpendicular to the basilar membrane) is visible. Using the pencil tool in Photoshop, the plasma membranes of all marginal, intermediate, and basal cells were traced within a box spanning the entire strial width and corresponding to $15 \mu \mathrm{m}$ of strial height. The total number of pixels in each tracing was computed and divided by the number of pixels in a line $1 \mu \mathrm{m}$ long, thus estimating the total linear distance of plasma membrane present in each micrograph.

Spiral ligament fibrocytes. An observer estimated, in every section through the cochlear duct, the percentage of remaining fibrocytes in each class (Type I, II, or IV). A quartile scale was employed (0-25\%, 25$50 \%, 50-75 \%$, or $75-100 \%$ of cells remaining). Estimates of cell loss were performed with a $10 \mathrm{X}$ or $20 \mathrm{X}$ objective, were based on cell nuclei, and were referred to the cell density seen in control ears. Care was taken to assess each cochlear region separately because the detailed appearance of the spiral ligament changes dramatically from base to apex in all murine strains we examined: $\mathrm{CBA} / \mathrm{CaJ}, \mathrm{C} 57 \mathrm{BL} / 6 \mathrm{~J}$, 129/SvEv, and FVB/N.

\section{RESULTS}

Overview of the patterns of threshold shift and damage to the organ of Corti

To put the lateral wall damage and EP shifts in proper context, it is important to summarize the pattern and degree of noise-induced threshold shifts and the damage to the organ of Corti for the noise exposures (94-116 dB) and survivals (0 h-8 weeks) used in the present study (for further details, see Wang et al.
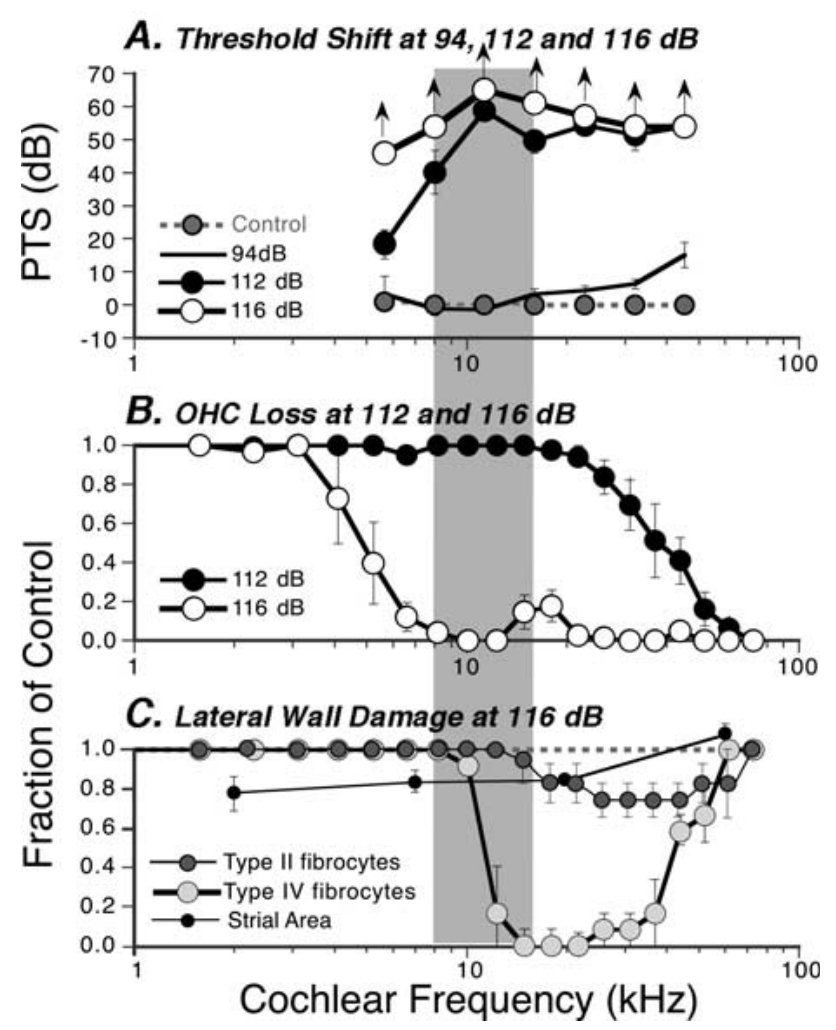

FIG. 1. $A B R$ threshold shifts and quantitative morphometry of cellular damage 2 weeks after acoustic injury. A. Mean threshold shifts $( \pm$ SEM) measured by $A B R$ after 94,112 , and $116 \mathrm{~dB}$ exposures re: control nonexposed littermates ( $n=4$ animals per group). B. Mean fractional survival $\left({ }_{ \pm}\right.$SEM) of first row of outer hair cells for groups exposed at 112 and $116 \mathrm{~dB}$ ( $n=4$ animals per group). C. Mean estimates of cell survival in the spiral ligament and stria vascularis after $116 \mathrm{~dB}$ exposure ( $n=4$ animals per group). Fibrocyte cell survival is an estimate of cells present re: control ears; strial integrity is a measure of changes in strialcross-sectional area re: control ears. Data are replotted from a previous report (Wang et al. 2002).

2002). The $94 \mathrm{~dB}$ exposure was designed to be at the border between reversible and irreversible damage. That is, when measured at $24 \mathrm{~h}$ postexposure, there was a peak threshold shift of $\sim 50 \mathrm{~dB}$ (data not shown) which resolved by 2 weeks postexposure to a minimal PTS of $<10 \mathrm{~dB}$, as illustrated in the top panel of Figure 1. All higher-level exposures produced significant to profound PTS; for example, the $112 \mathrm{~dB}$ exposures produced a mean peak PTS of $\sim 60 \mathrm{~dB}$ for all test frequencies $\geq 11.3 \mathrm{kHz}$, and the $116 \mathrm{~dB}$ exposure group was essentially nonresponsive at all test frequencies.

For exposures at SPLs $\leq 112 \mathrm{~dB}$, there was no significant loss of inner hair cells (data not shown) and outer hair cell loss was restricted to the extreme basal turn (hook region) of the cochlea (Fig. 1B). At $116 \mathrm{~dB}$, at early postexposure survivals, many ears showed a focal cochlear region in which the reticular lamina was ruptured at the junction between the 

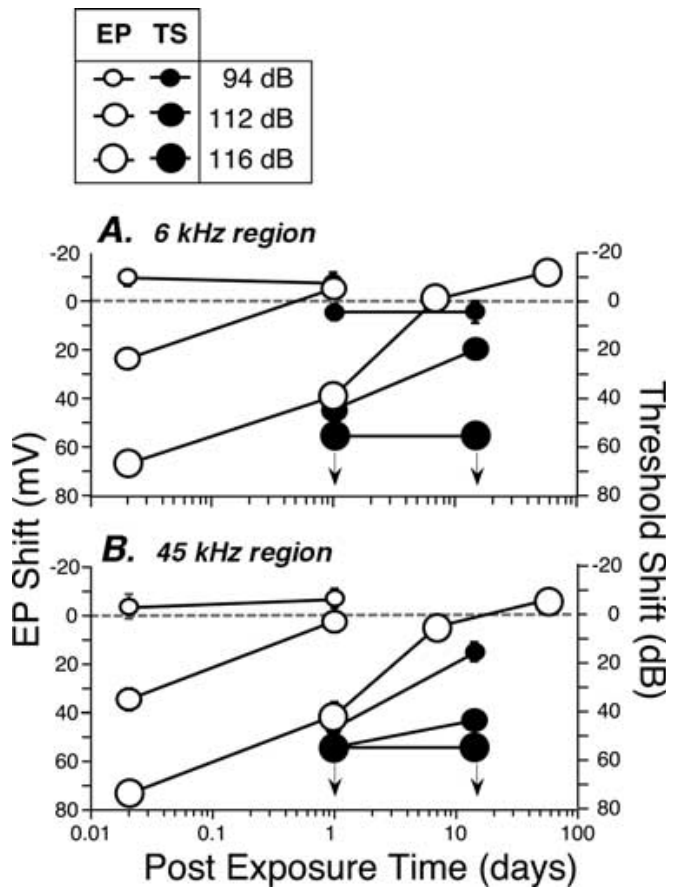

FIG. 2. Endocochlear potential (EP) shift re: control means and ABR threshold shift (TS) re: control means plotted against postexposure time for measurements at two cochlear locations. A and B. EP measurements from the second turn and first turn, respectively, each compared with ABR threshold shifts at the test frequency appropriate for that cochlear location. Animals in each group were: Control: $n=13 ; 116 \mathrm{~dB} / 0 \mathrm{~h}: n=8 ; 116 \mathrm{~dB} / 24 \mathrm{~h}: n=13 ; 116 \mathrm{~dB} / 7$ days: $n=7 ; 116 \mathrm{~dB} / 8$ weeks: $n=7 ; 112 \mathrm{~dB} / 0 \mathrm{~h}: n=7 ; 112 \mathrm{~dB} / 24 \mathrm{~h}$ : $n=7 ; 94 \mathrm{~dB} / 0 \mathrm{~h}: n=6 ; 94 \mathrm{~dB} / 24 \mathrm{~h}: n=6$.

outer pillar and first-row outer hair cells. As indicated in Figure 1B, this region presumably corresponds roughly to the cochlear locus tonotopically appropriate to the spectrum of the noise band. At longer survivals, this damage resolved to a similarly located focal region of inner hair cell loss (data not shown) and to virtually complete loss of all outer hair cells throughout the basal half of the cochlea (Fig. 1B).

\section{Endocochlear potential shifts}

As summarized in Figure 2, endocochlear potentials were recorded in both apical and basal turns from groups of mice exposed to either 94, 112, or $116 \mathrm{~dB}$ and at postexposure survival times ranging from $0 \mathrm{~h}$ to 8 weeks. According to 3D reconstructions of sectioned cochleas prepared after such recordings, the cochlear locations of the two penetration sites correspond to the 6 and $45 \mathrm{kHz}$ regions of the cochlea. In recordings from 20 control ears, the mean EPs recorded from apical and basal loci were +86 $(\mathrm{SEM}=2.01 \mathrm{mV})$ and $+101 \mathrm{mV}(\mathrm{SEM}=3.79 \mathrm{mV})$, respectively. These values are comparable to those measured in previous studies (Cable et al. 1992; Sadanaga and Morimitsu 1995; Minowa et al. 1999).
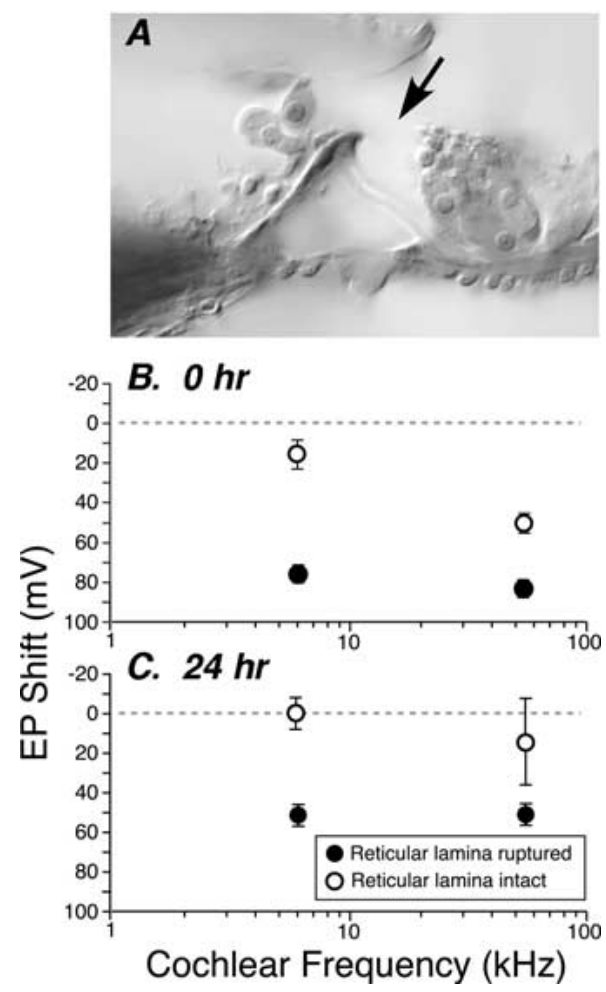

FIG. 3. Endocochlear potential and reticular lamina integrity after exposure to $116 \mathrm{~dB}$. A. Light micrograph showing the rupture of the reticular lamina (arrow) seen acutely in the tonotopic damage focus in many ears exposed at $116 \mathrm{~dB}$. B and C. Mean EP $( \pm$ SEM) plotted versus cochlear frequency with subjects divided into two groups: those with intact reticular lamina (RL) and those with RL rupture in the tonotopic focus. Numbers of subjects in each group were: $0 \mathrm{~h} \mathrm{w} /$ RL rupture: $n=4,0 \mathrm{~h} \mathrm{w} / \mathrm{RL}$ intact: $n=4 ; 24 \mathrm{~h}$ w/RL rupture: $n=4 ; 0$ h w/RL intact: $n=3$.

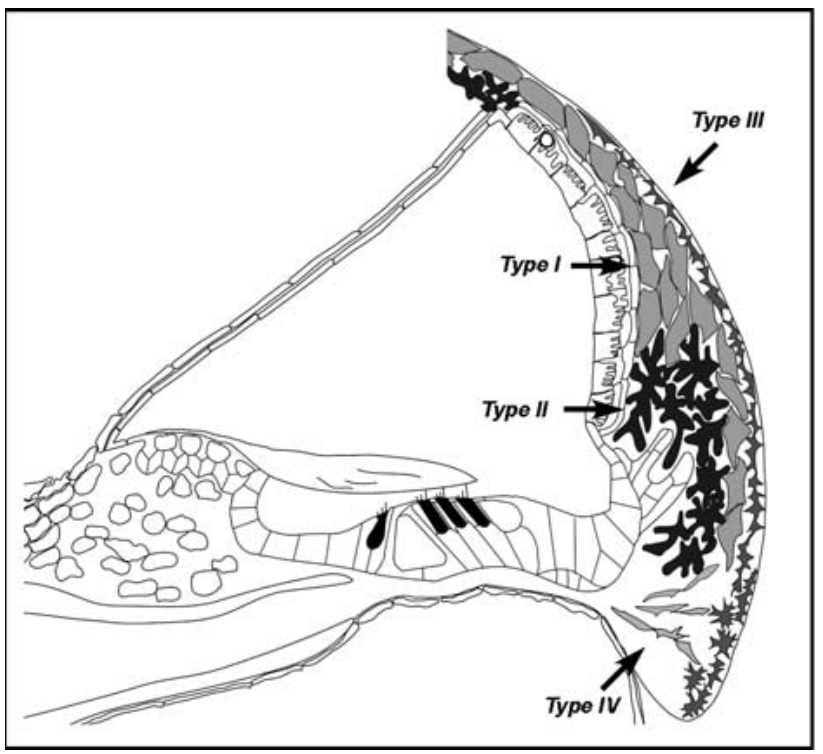

FIG. 4. Schematic drawing of the cochlear duct illustrates the spatial organization of the four fibrocyte classes in the spiral ligament. 


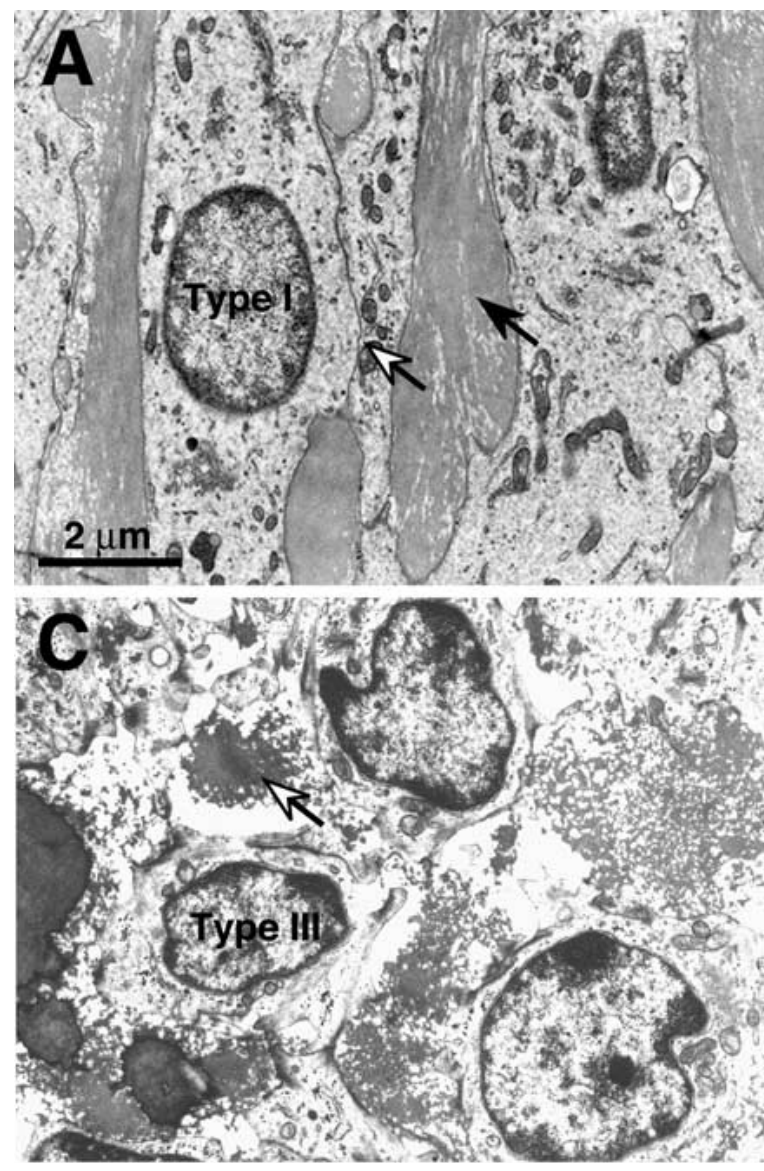

FIG. 5. Ultrastructure of normal spiral ligament fibrocytes. A. Type I fibrocytes are electron-lucent, associated with collagen bundles (black arrow), and connected by gap junctions (white arrow). B. Type II fibrocytes are associated with root cells, rich in mitochondria (white arrow), and have extensive interdigitating processes (black arrow) with adjacent type II cells. C. Type III fibrocytes appear round

There was no significant change in EP after $94 \mathrm{~dB}$ exposure, either 0 or $24 \mathrm{~h}$ postexposure. In Figure 2, EP values are normalized and plotted as shifts re control, to allow comparison to ABR threshold shifts measured in the same groups. Such comparison demonstrates that the TTS measured at $45 \mathrm{kHz}$ at 1 day after $94 \mathrm{~dB}$ exposure is not a result of changes in EP.

For the $112 \mathrm{~dB}$ exposure, EP was reduced by 22-35 $\mathrm{mV}$ immediately after noise, but recovered to control values within $24 \mathrm{~h}$. After $116 \mathrm{~dB}$, there was a larger EP drop $(65-73 \mathrm{mV})$ that recovered within $\sim 1$ week after noise. For the $112 \mathrm{~dB}$ exposure, the EP shift and recovery may contribute to the ABR shift and recovery occurring a few days later (Fig. 2). For the $116 \mathrm{~dB}$ exposure, the ABR shift exceeded the measurement capacity of the system, thus, comparison of the two recovery curves is impossible.

The magnitude of EP shift after $116 \mathrm{~dB}$ was strongly influenced by the disruption of the reticular lamina. As summarized above, most of the ears exposed to $116 \mathrm{~dB}$ showed rupture of the reticular

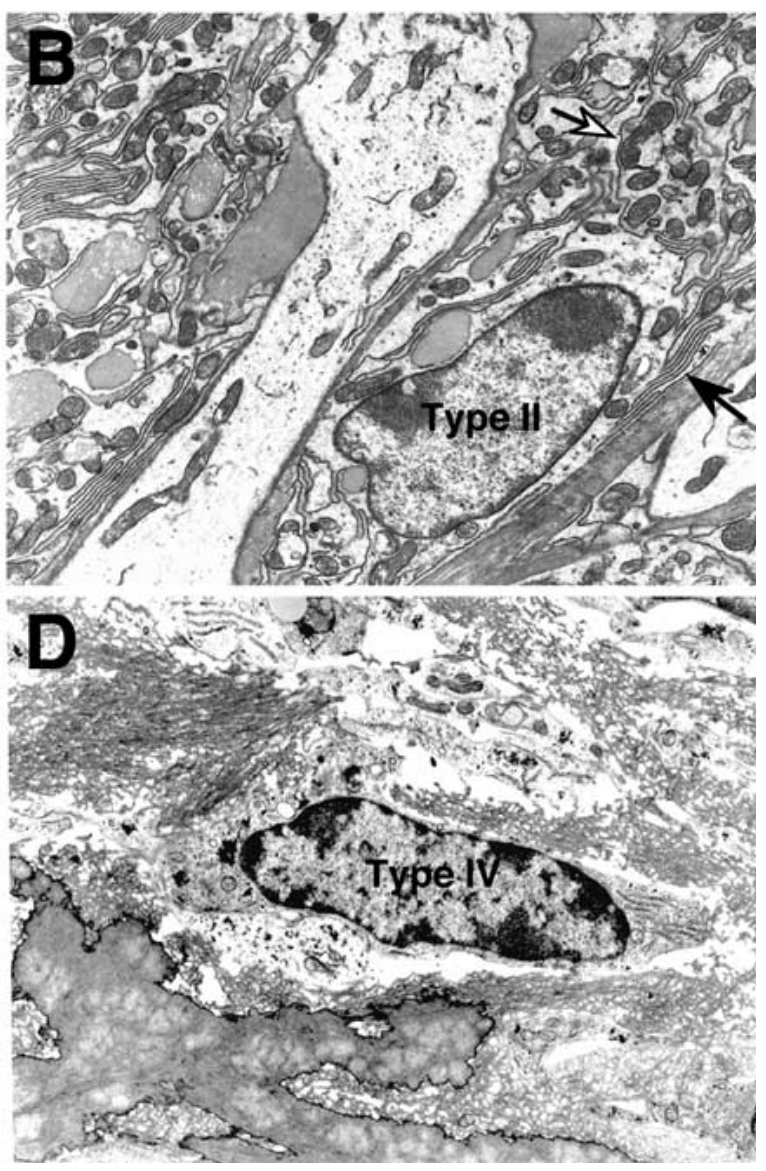

in cross-section due to their circumferential orientation with respect to the cochlear spiral and are associated with spiraling collagen bundles (white arrow). D. Type IV fibrocytes are fusiform, contain scant granular cytoplasm, and do not have the extensive processes of the type II cells. Scale bar applies to A-D.

lamina in a focal region in the middle of the cochlea (Fig. 3A); however, a minority did not. When the cochleas were separated according to this variable, there was a significant difference in magnitude and recovery time of the EP shifts. As illustrated in Figure 3B and $\mathrm{C}$, mice exposed to $116 \mathrm{~dB}$, that did not show reticular lamina rupture, demonstrated EP shifts similar in magnitude to those seen after $112 \mathrm{~dB}$, at both 0 and $24 \mathrm{~h}$ after exposure.

Normal morphology of lateral wall structures in the murine cochlea

The cochlear lateral wall, including spiral ligament and stria vascularis, plays an integral role in the creation of the endolymphatic potential (EP). Fibrocytes of the spiral ligament are divided into four cell types (Spicer and Schulte 1991, 1996; Slepecky 1996) based on histologic characteristics, immunostaining patterns, and general location (Fig. 4). Ultrastructural characteristics of these cells are illustrated in Figure 5. Type I 


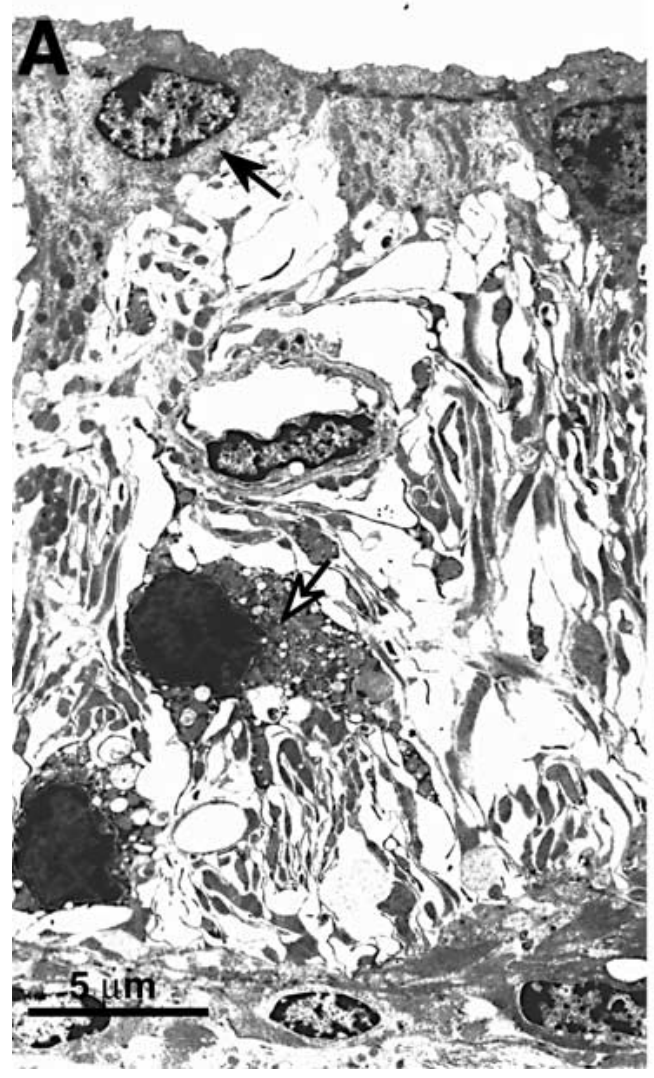

\section{B}

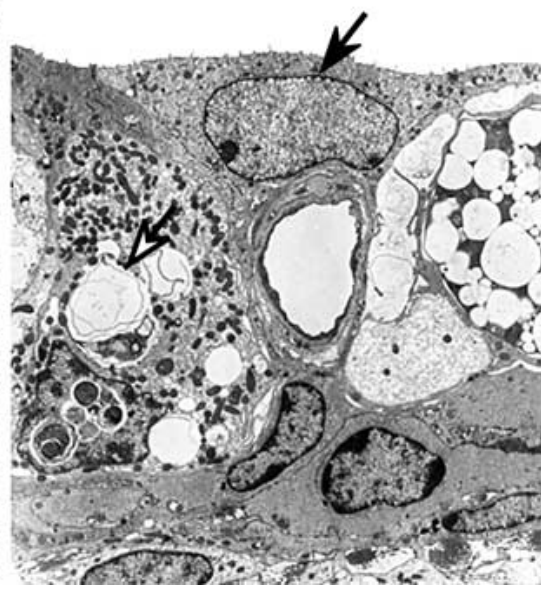

FIG. 8. Ultrastructural changes in the stria vascularis after exposure to $116 \mathrm{~dB}$. A. Eight hours after exposure in the upper basal turn (approximately $22 \mathrm{kHz}$ region), marginal cells are swollen (black arrow), intermediate cells are shrunken and pyknotic (white arrow), and large intercellular spaces form between processes of marginal and intermediate cells. B. Two weeks after noise exposure in the lower apical turn at approximately $6 \mathrm{kHz}$, the stria is thin and atrophio, marginal cells (black arrow) lack interdigitated processes, and intermediate cells are disintegrated (white arrow). Scale bar applies to A and B.

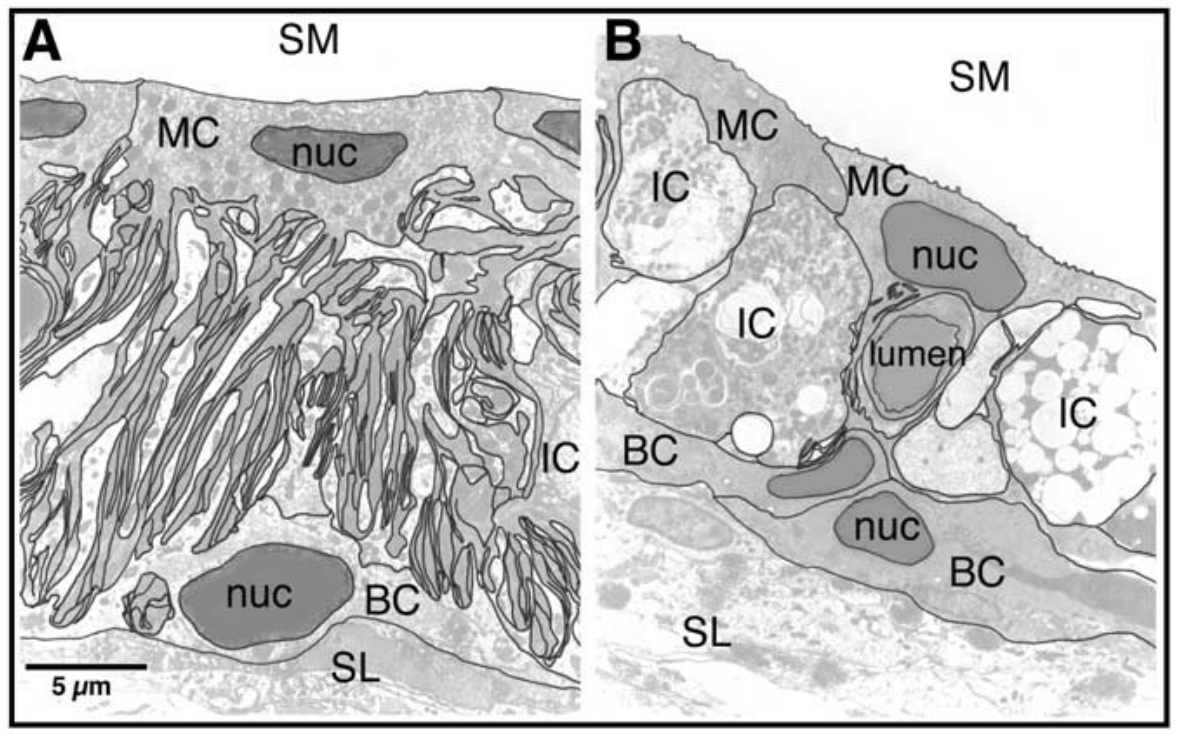

FIG. 9. After $116 \mathrm{~dB}$ noise exposure, marginal and intermediate cells of the stria vascularis show extensive loss of membrane surface area. $\mathbf{A}$ and $\mathbf{B}$. Tracings of all apposing membrane surfaces superimposed on electron micrographs from (A) a control stria and (B) a stria 4 weeks after $116 \mathrm{~dB}$. Both micrographs are from the upper basal turn. Note that this example demonstrates a roughly 50 decrease in strial cross sectional area, whereas the mean reduction for this cochlear region was $\sim 20$ (Fig. 1C). SM = scala media; $\mathrm{MC}=$ marginal cell; IC = intermediate cell; $\mathrm{BC}=$ basal cell; nuc = nucleus; $\mathrm{SL}=$ spiral ligament; lumen = endothelial cell lumen. Scale bar applies to A and B.

in gap junction continuity with type I and type II fibrocytes (Schulte and Steel 1994).

Lateral wall histopathology: light microscopic (LM) observations

At the LM level, noise-induced changes in the lateral wall differ in acute (within $24 \mathrm{~h}$ postexposure) vs. chronic (2 weeks postexposure) states. Changes visible at the LM level included acute swelling and chronic shrinkage of the stria vascularis as well as acute vacuolization and chronic degeneration of the type II and type IV fibrocytes.

As shown in Figure 7, acute swelling of the stria after $116 \mathrm{~dB}$ exposure is remarkable, even under light microscopy. Large spaces form within the ep- 

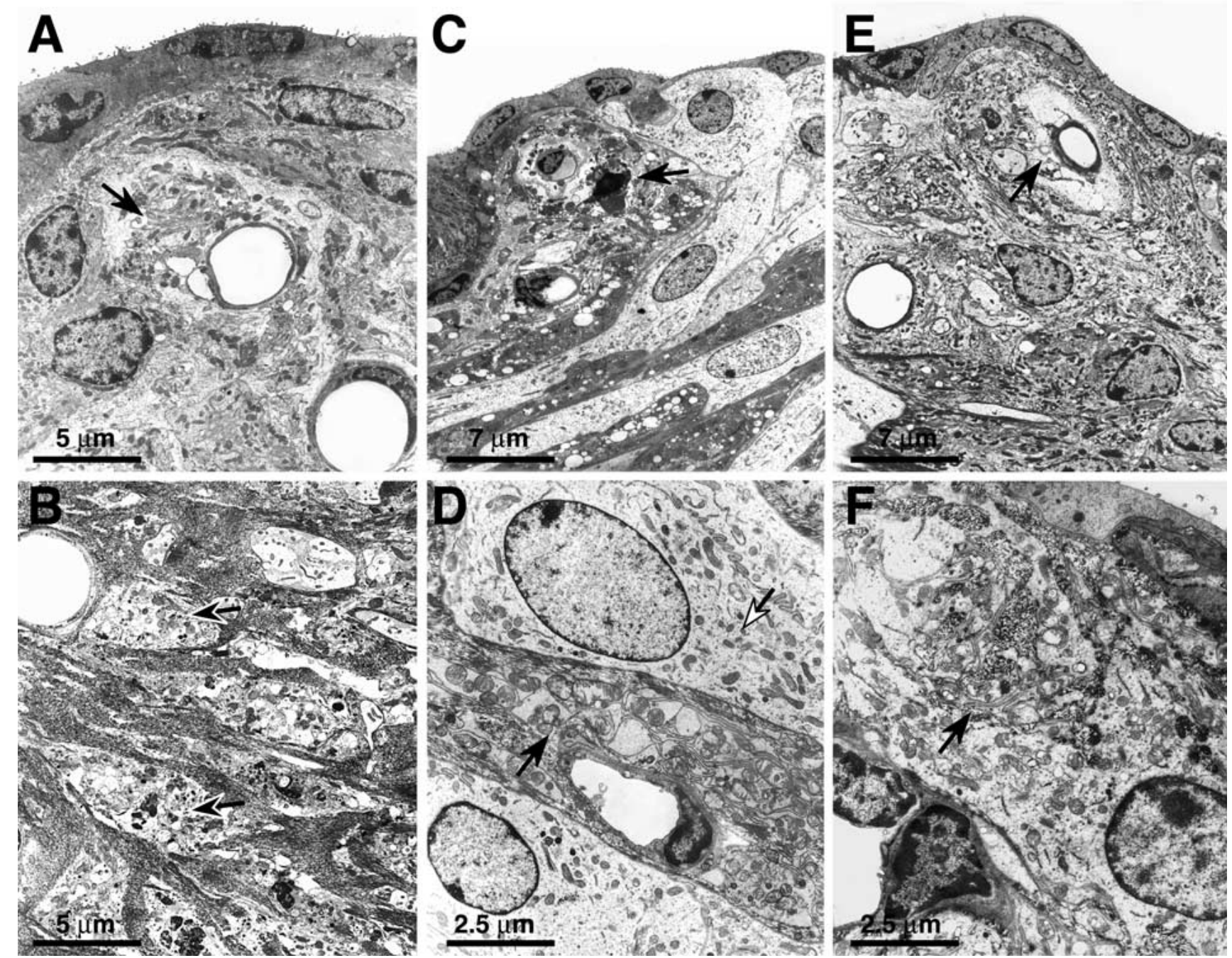

FIG. 10. Ultrastructural changes in type II fibrocytes after noise exposure. A. Zero hours after $100 \mathrm{~dB}$ exposure in the lower apical turn, degeneration of type II fibrocyte is seen in the spiral prominence (arrow). B. Twenty-four hours after exposure to 116 $\mathrm{dB}$ in the lower apical turn, cellular debris remains after lysis of type II fibrocytes (arrows). C. Eight hours after exposure to $116 \mathrm{~dB}$ in the upper basal turn, some type II fibrocytes are pyknotic with nuclear condensation (arrow). D. Twenty-four hours after exposure to $112 \mathrm{~dB}$ in the lower apical turn, mitochondrial swelling is seen within type II fibrocytes (black arrow); however, intervening root cells appear normal (white arrow). E. Two weeks after exposure to $116 \mathrm{~dB}$ in the lower basal turn, the spiral prominence shows loss of type II fibrocytes around the central vessel (arrow). F. Eight weeks after exposure to $116 \mathrm{~dB}$ in the lower apical turn, processes of type II fibrocytes are present in the spiral prominence (arrow), suggesting regeneration or repair of this cell type. ithelium (arrow in Fig. 7C), the marginal cell nuclei are rounded and bulge into the lumen of scala media, and the vessel lumena appear dilated (compare Fig. 7A with C). LM morphometry (Wang et al. 2002) showed that acute swelling of the strial epithelium was significant for all exposure levels a $\geq 100 \mathrm{~dB}$, i.e., for all exposures, which would ultimately result in PTS. In the chronic state, 2 weeks and more after exposure the stria vascularis is degenerated and atrophic and gaps between cells persist. LM morphometry also showed the chronic atrophy of the epithelium to be significant for all exposures $\geq 100 \mathrm{~dB}$. The degree of strial shrinkage vs. cochlear location for the $116 \mathrm{~dB}$ exposures is illustrated in Figure 1C.

Type IV fibrocyte loss was striking under light microscopy at 1 week survival for all sound pressure levels. The loss of these cells was consistently confined to the $10-40 \mathrm{kHz}$ region (Fig. 1C). At the light microscopic level, type II fibrocyte loss was detectable only in the $116 \mathrm{~dB}$ group and was observed in the entire the basal turn (Fig. 1C). In the acute stage, i.e., $8 \mathrm{~h}$ after exposure, intracytoplasmic vacuoles were widespread in type II fibrocytes (arrow in Fig. 7B). At 2 weeks postexposure, type II fibrocytes have largely disappeared, both from the spiral prominence and 

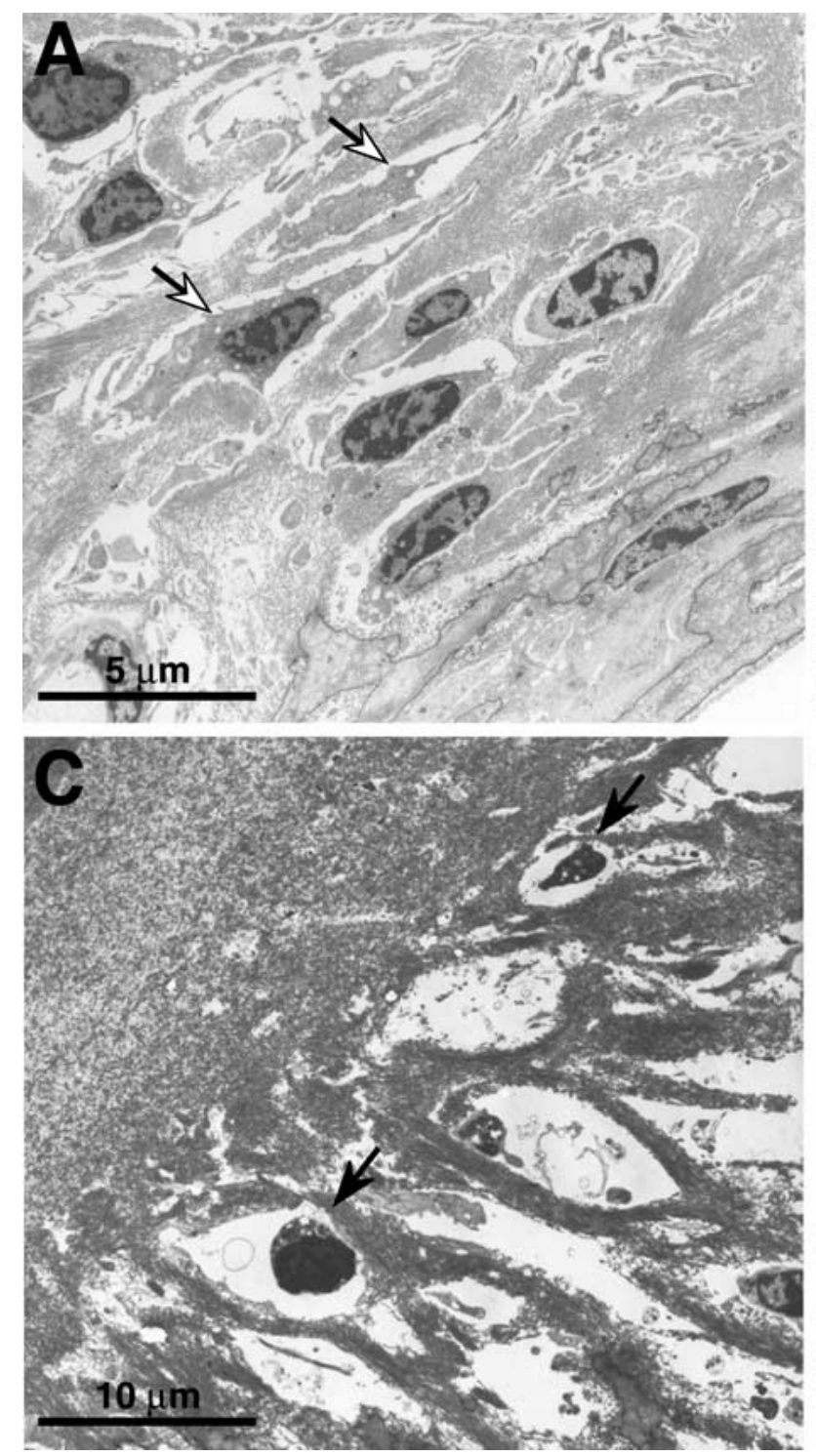

FIG. 11. Ultrastructural changes in type IV fibrocytes. A. Eight hours after exposure to $116 \mathrm{~dB}$ in the upper basal turn, type IV fibrocytes show cytoplasmic vacuolization and cell shrinkage (arrows). B. Two weeks after exposure to $116 \mathrm{~dB}$ in the lower basal turn, type IV fibrocytes (e.g., at arrow) show swollen nuclei and

from the more inferior portion of the ligament (arrows in Fig. 7D).

Lateral wall histopathology: electron microscopic (EM) observations

Stria vascularis. Electron microscopy demonstrates that acute strial swelling is largely due to an increase in extracellular space between marginal and intermediate cells (Fig. 8A) and partly due to marginal cell swelling. This transient swelling of the stria is accompanied by irreversible degeneration of intermediate cells: They undergo shrinkage, darkening, and
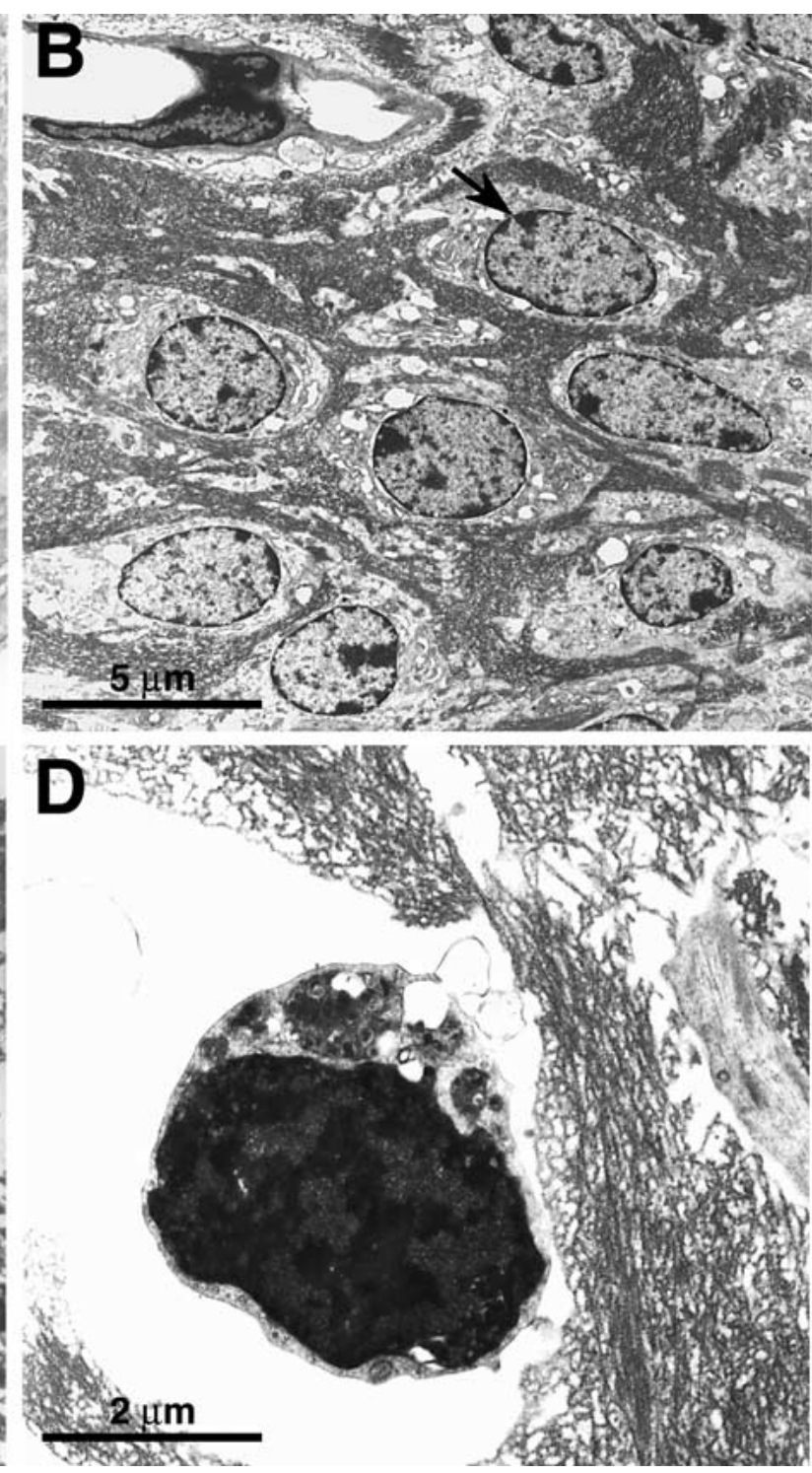

further cytoplasmic vacuolization C and D. Eight weeks after exposure to $116 \mathrm{~dB}$ in the lower basal turn, some type IV fibrocytes show residual apoptotic bodies (arrows in C), shrunken remnants of cells with condensed nuclear chromatin, and open collagen clefts.

vacuolization, consistent with apoptosis (Fig. 8A). By 2 weeks postexposure (Fig. 8B), the marginal cells have lost their processes and the intermediate cells appear to be undergoing phagocytosis by cells resembling macrophages. There is evidence of dark, condensed cellular debris within the cytoplasm of larger cells with multiple lobules reminiscent of pigmented melanocytes in the control ears. There are large clefts that have formed around the small vessels, and extracellular fluid appears accumulated in the perivascular spaces and between the marginal and intermediate cell processes. The basal cells normally form a continuous layer, with tight junctions between 
adjacent basal cells separating the strial compartment of the lateral wall from the spiral ligament. This barrier is disrupted after acoustic trauma, and gaps are seen between basal cells in the damaged lateral wall.

Over the next 2-8 weeks, the stria continues to shrink and intermediate cells degenerate. There is no indication of intermediate cell recovery. Thus, the amplified membrane that normally characterizes the intermediate/marginal cell apposition is greatly reduced 2-8 weeks after noise exposure. The thinning of the stria vascular was most severe in the regions where the reticular lamina was broken and less prominent in the high-frequency region of the cochlea. The plasma membrane of the three cell types of the stria is shown in Figure 9, demonstrating the dramatic loss of cell surface area after $116 \mathrm{~dB}$ noise exposure compared with the control ear. In the sections traced, there is an eightfold reduction in plasma membrane elaboration in the noise-damaged ear when compared with control. Presumably, these changes in surface area led to reduced ion transport. Although this was the only region in which this type of loss was quantified, visual inspection of many micrographs suggests that such changes are typical of the lateral wall after the $116 \mathrm{~dB}$ exposures. The loss of membrane surface area and loss of the intermediate cells were less dramatic but still present at $112 \mathrm{~dB}$ and lower exposures.

Type II fibrocytes. From an ultrastructural perspective, type II fibrocytes showed marked histopathology immediately after exposure for all SPLs $\geq 100$ (Fig. 10). At $0 \mathrm{~h}$ after $100 \mathrm{~dB}$ exposure (Fig. 10A), the type II cells in the spiral prominence region showed intracytoplasmic vacuolization, increased extracellular space around their processes, and breakdown of the plasma membrane. Within $24 \mathrm{~h}$, there was frank rupture of the type II cell membrane, with formation of darkened fragments of cellular membrane and debris (Fig. 10B,C). The adjacent root cells remain entirely normal (Fig. 10C,D). Figure 10C demonstrates the characteristic darkening and shrinkage of type II nuclei (arrow) and intracytoplasmic vacuolization. Figure $10 \mathrm{D}$ is a higher-magnification view of the type II fibrocyte (arrows) flanked by root cells, highlighting the intracellular swelling that results in blebbing of the processes and disruption of the mitochondrial cristae (arrows) caused by noise exposure leaving the root cell mitochondria intact. The degeneration patterns of type II fibrocytes were suggestive of a necrotic or lytic process. The cellular debris was ultimately cleared, although phagocytic cell migration was not observed directly. Root cells appeared to sequester some cellular fragments of the type II fibrocytes without any evidence of injury to the root cells themselves.
By 2 weeks postexposure, the spiral prominence is devoid of all cells except for root cell processes and vascular endothelial cells (Fig. 10E). However, 8 weeks after noise exposure, there is evidence that type II cells may have regenerated: the areas characterized by cell loss at the earlier survivals are now populated with some normal-appearing type II fibrocytes (Fig. $10 \mathrm{~F})$.

Type IV fibrocytes. The type IV fibrocytes also undergo degeneration, but the time course and morphology differ from that observed in the type II cells. Under light microscopy, cell loss was noted at 2 weeks postexposure. Using electron microscopy, early degenerative changes in the type IV fibrocytes were observed, but these changes were heterogeneous in nature. In some cases, type IV nuclei appeared shrunken, dark, and condensed (Fig. 11A). In other cases, the cells appeared swollen with rounded nuclei and cytoplasmic expansion and vacuolization (Fig. 11B). However, by 2 weeks postexposure, there was rampant cell loss with apoptotic bodies or cell fragments that were observed in the collagen clefts of the spiral ligament (Fig. 10C,D). These apoptotic bodies appear to be efficiently cleared during the 2-8 week period after acoustic injury. This region did not repopulate with fibrocytes during the observed period or up to 16 weeks after noise exposure.

Type I and Type III fibrocytes. Neither the type I nor the type III fibrocyte was reduced in number, but the collagen bundles in close association with these cells became dispersed and appeared distended by fluid, similar to the appearance of the strial marginal and intermediate cells.

\section{DISCUSSION}

EP shifts and their contributions to temporary and permanent threshold shifts

Data from the present study are consistent with previous reports suggesting that EP shifts do not occur after noise exposures resulting in temporary threshold shifts, no matter how severe. One report (Boettcher and Schmiedt 1995) examined gerbils following repeated daily exposure to $6 \mathrm{~h}$ of noise at $80 \mathrm{~dB}$ SPL and found no significant EP changes at a postexposure time at which there was minimal TTS $(\sim 10 \mathrm{~dB}$ shift). Another group examined rats after a $30 \mathrm{~min}$ exposure to $100 \mathrm{~dB}$ noise and found no EP shifts at a postexposure time at which there was $20 \mathrm{~dB}$ of TTS (Ma et al. 1995). An early study (Benitez et al. 1972) examined a severe TTS (48 dB) measured after a 7 day exposure to an octave band of noise at $95 \mathrm{~dB}$ SPL and also found no EP shifts. In the present study, we examined a severe TTS $(\sim 50 \mathrm{~dB})$, which is just at the 
border of reversibility. Thresholds measured 2 weeks postexposure to $94 \mathrm{~dB}$ noise (Fig. 1) show a small (but significant) permanent loss. Nevertheless, even when measured almost immediately after exposure, the EP was not significantly shifted from normal. Thus, it appears safe to conclude that the threshold elevations accompanying reversible threshold shifts, and measured in the hours and days after exposure, are not caused by any changes in EP. There may be transient changes in EP that occur during traumatic exposures; however, these changes appear to be small and to revert to baseline values within seconds or minutes after termination of the exposure (Salt and Konishi 1979; Wang et al. 1992).

There have been fewer studies of EP shifts in ears with permanent noise-induced hearing loss. One report (Ide and Morimitsu 1990), using $4 \mathrm{~h}$ exposures to $145 \mathrm{~dB}$ pure tones in guinea pig, reported a significant postexposure drop in EP, which recovered to baseline after 5 days. A study by Wang et al. (1990) demonstrated EP decrements after 20-80 min exposure to $125 \mathrm{~dB}$ white noise. EP recovered within 1 week postexposure, and the loss was proportional to exposure duration. However, threshold shifts were not measured in either study; thus, one can only infer, based on the sound pressure and duration of the exposures, that there was a PTS. These patterns of EP drop and recovery are similar to those in the present study (Fig. 2), showing significant EP drops following both 112 and $116 \mathrm{~dB}$ exposures. The initial response to $112 \mathrm{~dB}$ included a transient $22-35 \mathrm{mV}$ drop in EP and rapid recovery during the first $24 \mathrm{~h}$. Immediately after the $116 \mathrm{~dB}$ exposure, there was a mean EP shift of $\sim 70 \mathrm{~dB}$, which required about 7 days for full recovery. According to studies with furosemide, which decreases EP by interfering with ion transport, there is a roughly $1 \mathrm{~dB}$ shift in compound action potential threshold for every $1 \mathrm{mV}$ decrement in EP (Sewell 1984). Thus, in cases of noise exposure that will result in PTS, any recovery of hearing thresholds within the first few days after exposure includes a significant contribution from recovery of the EP. However, it is clear that, in the steady state, permanent noise-induced hearing loss is not caused by alterations in EP, given that these EP shifts have consistently recovered to normal levels within 1 week after exposure.

\section{Dynamics of cochlear damage and associated changes in EP after noise exposure}

The lack of EP shift during a pure TTS, i.e., after the $94 \mathrm{~dB}$ exposure, correlated with the lack of visible morphological change in the stria or type II fibrocytes (Wang et al. 2002). On the other hand, there was massive degeneration of type IV fibrocytes throughout much of the basal turn 2 weeks following these exposures. Clearly, type IV fibrocytes are not required for normal EP generation.

For the 112 and $116 \mathrm{~dB}$ exposures, which caused large EP changes acutely after noise (Fig. 2), there was clearcut histopathology in many structures of the lateral wall, including strial marginal and intermediate cells as well as type II and type IV fibrocytes. The earliest changes were seen in the type II fibrocytes, which exhibited extensive cytoplasmic vacuolization immediately after these noise exposures (Fig. 10), i.e., at a time when the EP shifts were maximal. In contrast, changes in the stria vascularis were not dramatic at the earliest postexposure survivals. At these immediate postexposure times, the most important factor in determining the degree of EP shift appeared to be the integrity of the reticular lamina: In cases where the reticular lamina was breached, the EP changes were significantly larger than in those cases where it appeared intact under light microscopy (Fig. $3)$. It is not surprising that EP should be severely affected by large holes in the electrochemical barrier between endolymph and perilymph.

By $24 \mathrm{~h}$ postexposure, the EP had recovered completely after $112 \mathrm{~dB}$ noise. Even after the $116 \mathrm{~dB}$ exposure, EP had largely recovered, especially in those cases with intact reticular lamina (Figs. 2 and 3). Paradoxically, it is at this postexposure time that swelling of the stria vascularis was at its worst (Fig. 7; and Wang et al. 2002), suggesting that the swelling reflects part of the recovery process. Strial swelling likely reflects volume expansion in response to an osmotic challenge arising from increased solute load, i.e., potassium flux. This flux must be largely due to the frank ruptures of the reticular lamina (Fig. 3), but may also be due to increased flux through transduction channels during acoustic overexposure. Strial marginal cells have been noted to be primary osmoregulators and not effective volume regulators and, thus, are susceptible to large shifts in volume in response to changes in osmolarity (Wangemann et al. 2002). Previous ultrastructural investigations (Ide and Morimitsu 1990) have also noted extracellular edema and separation of marginal and intermediate cells at survival times $\leq 24 \mathrm{~h}$.

By 2 weeks after noise exposure, there were few type II fibrocytes remaining in the spiral ligament (Fig. 7D) and the stria vascularis was atrophic throughout much the cochlea (Fig. 8B). Based on estimates made in the lower basal turn of one ear exposed to $116 \mathrm{~dB}$, the membrane area of interdigitations between marginal and intermediate cells, where much of the ion pumping capacity of the stria is thought to reside, had decreased roughly an order of magnitude (Figs. 8 and $9)$. Despite this dramatic and widespread damage to lateral wall structures throughout the basal turn, the EP had returned to normal values, both in the apical and in the basal turns (Fig. 2). 
Previous work has also suggested there is redundancy in strial pumping capacity. For example, strial atrophy in the aging gerbil ear can cause up to $60 \%$ reduction in cross-sectional area, yet be associated with $<20 \mathrm{mV}$ reductions in EP (Schulte and Schmiedt 1992). In the present study, a further contributing factor may be the widespread loss of hair cells and damage to stereocilia at $116 \mathrm{~dB}$. The silencing of transduction associated with these structural changes eliminates a large source of transepithelial currents in the ear. This may, in turn, make it easier to maintain a normal EP with what must be dramatically reduced pumping capacity in the lateral wall.

At 8 weeks postexposure, data from the present study suggested that there might be regeneration of cells in the lateral wall, particularly among the type II fibrocytes (Fig. 10). Repopulation of cells in the stria vascularis or type IV fibrocyte region was not observed in this study, but the type II fibrocytes, which were decimated in the spiral prominence at 2 weeks, appear to be present, with extensive interdigitating processes, at 8 weeks. Evidence for proliferation of several lateral wall cell types was offered in a previous study of noise damage in the gerbil (Roberson and Rubel 1994) in which tritiated thymidine was used to assay cell division in the cochlea. There were increased numbers of labeled cells in the spiral ligament, in both the type II and the type IV fibrocyte regions, as well as in the stria vascularis. Nonetheless, the impact on recovery of hearing function would be minimal given widespread damage to sensory cells and the fact that that neither repopulation of sensory cells nor recovery of lost or fused stereocilia has been observed in this setting.

In summary, the present data suggest that lateral wall damage plays a minor role in shaping the magnitude of hearing loss in either temporary or permanent noise-induced hearing loss, primarily because damage to these structures is coupled with such severe damage to the organ of Corti that hearing is already severely compromised. On the other hand, selective damage to the lateral wall, in the absence of organ of Corti damage clearly can have important effects on hearing levels. For example, in a mouse model of DFN3, with targeted deletion of the BRN-4 gene, there is normal hair cell and spiral ganglion cell development associated with abnormalities in type I, II, and III fibrocytes (Minowa et al. 1999). In these mice, EP is decreased and ABR thresholds are elevated. Similarly, damage to lateral wall structures appears to be of greater functional significance in age-related hearing loss, at least in the gerbil; the slowly progressing loss of threshold sensitivity at high frequencies is associated with a progressive loss of EP and cellular integrity in the lateral wall which appears to precede damage to the sensory cells
(Gratton et al. 1995). Both of these studies suggest that pathology in the stria vascularis and in the spiral ligament observed after acoustic trauma could have had more significant impact on hearing had there been preservation of the primary sensory apparatus.

\section{ACKNOWLEDGMENTS}

Research supported by RO1 DC 00188 from the NIDCD and funds from the Department of Otology and Laryngology at the Massachusetts Eye and Ear Infirmary.

\section{REFERENCES}

Anniko M, Nordemar H. Embryogenesis of the inner ear. IV. Postnatal maturation of the secretory epithelia of the inner ear in correlation with the elemental composition in the endolymphatic space. Arch. Otorhinolaryngol. 229:281-288, 1980.

Benitez LD, Eldredge DH, Templer JW. Temporary threshold shifts in chinchilla: electro-physiological correlates. J. Acoust. Soc. Am. 52:1115-1123, 1972.

Boettcher FA, Schmiedt RA. Distortion-product otoacoustic emissions in Mongolian gerbils with resistance to noise-induced hearing loss. J. Acoust. Soc. Am. 98:3215-3222, 1995.

Cable J, Barkway C, Steel KP. Characteristics of stria vascularis melanocytes of viable dominant spotting (Wv/Wv) mouse mutants. Hear. Res. 64:6-20, 1992.

Crouch JJ, Sakaguchi N, Lytle C, Schulte BA. Immunohistochemical localization of the $\mathrm{Na}-\mathrm{K}-\mathrm{Cl}$ co-transporter (NKCC1) in the gerbil inner ear. J. Histochem. Cytochem. 45:773-778, 1997.

EHret G. Peripheral anatomy and physiology II. In: WiLlot JF (ed) The Auditory Psychobiology of the Mouse. Charles C. Thomas, Springfield, IL, pp 169-200, 1983.

Gratton MA, Schulte BA. Alterations in microvasculature are associated with atrophy of the stria vascularis in quiet-aged gerbils. Hear. Res. 82:44-52, 1995.

Gratton MA, Smyth BJ, Schulte BA, Vincent Jr DA. Na,K-ATPase activity decreases in the cochlear lateral wall of quiet-aged gerbils. Hear. Res. 83:43-50, 1995.

Gratton MA, Schmiedt RA, Schulte BA. Age-related decreases in endocochlear potential are associated with vascular abnormalities in the stria vascularis. Hear. Res. 94:116-124, 1996.

Hakuba N, Koga K, Gyo K, Usami SI, Tanaka K. Exacerbation of noise-induced hearing loss in mice lacking the glutamate transporter GLAST. J. Neurosci. 20:8750-8753, 2000.

Henderson D, Spongr V, Subramaniam M, Campo P. Anatomical effects of impact noise. Hear. Res. 76:101-117, 1994.

Hequembourg S, Liberman MC. Spiral ligament pathology: a major aspect of age-related cochlear degeneration in C57BL/ 6 mice. J. Assoc. Res. Otolaryngol. 2:118-129, 2001.

Hinojosa R, Rodriguez-Echandia EL. The fine structure of the stria vascularis of the cat inner ear. Am. J. Anat. 118:631-663, 1966.

Ichimira I, Suzuki M, Mogi G. Age-related changes in the murine cochlear lateral wall. Hear. Res. 139:116-122, 2000.

Ide M, Morimitsu T. Long term effects of intense sound on endocochlear DC potential. Auris Nasus Larynx 17:1-10, 1990.

JAHNKE K. Intercellular junctions in the guinea pig stria vascularis as shown by freeze-etching (author's translation). Anat. Embryol. (Berl.) 147:189-201, 1975. 
Li W, ZhaO L, JiAng S, Gu R. Effects of high intensity impulse noise on ionic concentrations in cochlear endolymph of the guinea pig. Chin. Med. J. (Engl.) 110:883-886, 1997.

Liberman MC, Kiang NY. Acoustic trauma in cats. Cochlear pathology and auditory nerve activity. Acta Otolaryngol. Suppl. 358:1-63, 1978.

Liberman MC, Dodns LW. Single-neuron labeling and chronic cochlear pathology. III. Stereocilia damage and alterations of threshold tuning curves. Hear. Res. 16:55-74, 1984.

Ma YL, Gerhardt KJ, Curtis LM, Rybak LP, Whitworth C, Rarey KE. Combined effects of adrenalectomy and noise exposure on compound action potentials, endocochlear potentials and endolymphatic potassium concentrations. Hear. Res. 91:79-86, 1995.

Minowa O, Ikeda K, Sugitani Y, Oshima T, Nakai S, Katori Y, Suzuki M, Furukawa M, Kawase T, Zheng Y, Ogura M, Asada Y, Watanabe $\mathrm{K}$, Yamanaka $\mathrm{H}$, Gotoh S, Nishi-Takeshima M, Sugimoto T, Kikuchi T, Takasaka T, Noda T. Altered cochlear fibrocytes in a mouse model of DFN3 nonsyndromic deafness. Science 285:1408-1411, 1999.

Offner FF, Dallos P, Cheatham MA. Positive endocochlear potential: mechanism of production by marginal cells of stria vascularis. Hear. Res. 29:117-124, 1987.

Ohlemiller KK, McFadden SL, Ding DL, Flood DG, Reaume AG, Hoffman EK, Scott RW, Wright JS, Putcha GV, Salvi RJ. Targeted deletion of the cytosolic $\mathrm{Cu} / \mathrm{Zn}$-superoxide dismutase gene (Sod1) increases susceptibility to noise-induced hearing loss. Audiol. Neurootol. 4:237-246, 1999.

Ou HC, Bohne BA, Harding GW. Noise damage in the C57BL/CBA mouse cochlea. Hear. Res. 145:111-122, 2000.

Prosen CA, Bath KG, Vetter DE, May BJ. Behavioral assessments of auditory sensitivity in transgenic mice. J. Neurosci. Meth. 97:5967, 2000.

Puel JL, Ruel J, Gervais d’Aldin C, Pujol R. Excitotoxicity and repair of cochlear synapses after noise-trauma induced hearing loss. Neuroreport 9:2109-2114, 1998.

Roberson DW, Rubel EW. Cell division in the gerbil cochlea after acoustic trauma. Am. J Otol. 15:28-34, 1994.

ROBERTSON D. Effects of acoustic trauma on stereocilia structure and spiral ganglion cell tuning properties in the guinea pig cochlea. Hear. Res. 7:55-74, 1982.

RoBERTSON D. Functional significance of dendritic swelling after loud sounds in the guinea pig cochlea. Hear. Res. 9:263-278, 1983.

Robertson D, Johnstone BM. Acoustic trauma in the guinea pig cochlea: early changes in ultrastructure and neural threshold. Hear. Res. 3:167-179, 1980.

Sadanaga M, Morimitsu T. Development of endocochlear potential and its negative component in mouse cochlea. Hear. Res. 89:155-161, 1995.

Salt AN, Konishi T. Effects of noise on cochlear potentials and endolymph potassium concentration recorded with potassiumselective electrodes. Hear. Res. 1:343-363, 1979.

Salt AN, Melichar I, Thalmann R. Mechanisms of endocochlear potential generation by stria vascularis. Laryngoscope 97:984991, 1987.

SANTOS-SACCHI J. An electronmicroscopic study of microtubules in the development of marginal cells of the mouse stria vascularis. Hear. Res. 6:7-13, 1982.
Schulte BA, AdAms JC. Distribution of immunoreactive $\mathrm{Na}^{+}, \mathrm{K}^{+}-$ ATPase in gerbil cochlea. J. Histochem. Cytochem. 37:127-134, 1989.

Schulte BA, Schmiedt RA. Lateral wall Na,K-ATPase and endocochlear potentials decline with age in quiet reared gerbils. Hear. Res. 61:35-46, 1992.

Schulte BA, STEel KP. Expression of alpha and beta subunit isoforms of Na,K-ATPase in the mouse inner ear and changes with mutations at the Wv or Sld loci. Hear. Res. 78:65-76, 1994.

SEWELl WF. The effects of furosemide on the endocochlear potential and auditory-nerve fiber tuning curves in cats. Hear. Res. 14:305-314, 1984.

SLEPECKY NB. Structure of the Mammalian Cochlea. In: Dallos P, Popper AN, FAY RR (eds) The Cochlea. Springer-Verlag, New York, pp 44-129, 1996.

Spicer SS, Schulte BA. Differentiation of inner ear fibrocytes according to their ion transport related activity. Hear. Res. 56:5364, 1991.

Sicer SS, Schulte BA. The fine structure of spiral ligament cells relates to ion return to the stria and varies with place-frequency. Hear. Res. 100:80-100, 1996.

Spicer SS, Gratton MA, Schulte BA. Expression patterns of ion transport enzymes in spiral ligament fibrocytes change in relation to strial atrophy in the aged gerbil cochlea. Hear. Res. 111:93-102, 1997.

TAKeuchi S, ANDO M. Inwardly rectifying $\mathrm{K}^{+}$currents in intermediate cells in the cochlea of gerbils: a possible contribution to the endocochlear potential. Neurosci. Lett. 247:175-178, 1998.

VAssout P. Effects of pure tone on endocochlear potential and potassium ion concentration in the guinea pig cochlea. Acta Otolaryngol. 98:199-203, 1984.

WAng J, Li Q, Dong W, Chen J. Effects of various noise exposures on endocochlear potentials correlated with cochlear gross responses. Hear. Res. 59:31-38, 1992.

WANG JA, Dong WJ, Chen JS. Changes in endocochlear potential during anoxia after intense noise exposure. Hear. Res. 44:143149, 1990.

Wang Y, Hirose K, Liberman MC. Dynamics of noise-induced cellular injury and repair in the mouse cochlea. J. Assoc. Res. Otolaryngol. 3:248-268, 2002.

WANGEMANN P. Comparison of ion transport mechanisms between vestibular dark cells and strial marginal cells. Hear. Res. 90:149157, 1995.

Wangemann P. Potassium ion secretion and generation of the endocochlear potential in the stria vascularis. HNO 45:205-209, 1997.

Wangemann P, Liu J, Marcus DC. Ion transport mechanisms responsible for $\mathrm{K}^{+}$secretion and the transepithelial voltage across marginal cells of stria vascularis in vitro. Hear. Res. 84:19-29, 1995.

Wangemann P, Scherer EQ, Lee JH, Marcus DC. K Secretion in Strial Marginal Cells and Vestibular Dark Cells is Controlled by the extracellular osmolarity. Assoc. Res. Otolaryngol. Abstr. p 4, 2002.

Yoshida N, Hequembourg SJ, Atencio CA, Rosowski JJ, Liberman MC. Acoustic injury in mice: $129 / \mathrm{SvEv}$ is exceptionally resistant to noise-induced hearing loss. Hear. Res. 141:97-106, 2000. 